\title{
Health, the forth pillar of sustainable development. A Rio+20 objective: prevention and precaution for cancer control in Africa
}

\section{La santé, quatrième pilier du développement durable. Un objectif pour Rio+20 : prévention et précaution pour le contrôle du cancer en Afrique}

\author{
A.J. Sasco \\ (C) Springer-Verlag France 2012
}

\section{Sustainable development and health}

What is to be done? (Lenin, 1902)

The Rio+20 United Nations (UN) Conference on Sustainable Development will be held in June 2012 in Brazil. Another UN Conference, the High-level Meeting of the General Assembly on the Prevention and Control of Non-Communicable Diseases (NCDs), took place in September 2011 in New York. Discussing the health of population, including the long forgotten issue of NCDs in countries of the South, and discussing pathways to sustainable development are excellent initiatives, which merit support.

As a mature cancer epidemiologist, am I satisfied with these events?

Well, yes and no.

Yes, because these two issues of a healthy and equitable world and of the prevention and control of noncommunicable diseases are the ones I have been fighting for all my life, both in my career and as a woman, a mother, and a citizen of the world, without ever feeling the need to separate these roles.

No, because these two domains, of development and of health, have too long been kept separate.

I fully acknowledge the importance of official recognition by the highest international authority of issues of both sustainable development and control of NCDs. Sustainable development was defined in April 1987 by the Brundtland Commission in the "Our Future" report as development that "meets the needs of the present without compromising the

A.J. Sasco $(\square)$

Epidemiology for Cancer Prevention, Team on HIV, Cancer and Global Health in resource limited settings, Inserm U897, Bordeaux Segalen University,

146, rue Leo-Saignat, F-33076 Bordeaux Cedex, France

e-mail : annie.sasco@isped.u-bordeaux2.fr ability of future generations to meet their own needs." The Commission's recommendations led to the Earth Summitthe United Nations Conference on Environment and Development (UNCED) in Rio de Janeiro in 1992, the 20th anniversary of which will be celebrated soon. The proposed three pillars of sustainable development for the past two decades have been economic, environmental, and social. Not much, if anything, was said about health, which may seem somewhat paradoxical if one realizes the woman who gave her name to the commission, Dr. Gro Harlem Brundtland, later became the Director General of the World Health Organization (WHO) from 1998 to 2003. A Harvard alumna, like myself, but most unlike me, an exceedingly powerful political woman, having been for many years a State Minister of the Norwegian government, and even Prime Minister, she tried to reform WHO, stating in her acceptance speech to the World Health Assembly: "What is our key mission? I see WHO's role as being the moral voice and the technical leader in improving health of the people of the world - ready and able to give advice on the key issues that can unleash development and alleviate suffering. I see our purpose to be combating disease and ill health, promoting sustainable and equitable health systems in all countries." She decided to serve only one term and left WHO at the end of her first mandate.

It is interesting to note that the need for a global, comprehensive approach on sustainable development was felt by the $\mathrm{UN}$ almost 20 years before the same institution decided to address the issue of control of chronic diseases. Part of this delay may lay in the fact that economy is the most universally recognized driving force of governments of the world, whereas health is only considered when it appears to be a problem, i.e. when diseases become a "threat to the economies (my emphasis added) of many Member States." I have learnt to understand and even pragmatically accept these economic considerations. Yet, as I wrote in September 2011 in an open letter to the United Nations Secretary 
General Ban Ki Moon and the World Health Organization Director General Dr Margaret Chan, which ended being signed by more than 160 doctors and scientists from 36 countries on all continents of the world " $(\mathrm{g})$ overnments of the world have an ethical responsibility to act to prevent part of these diseases. We support the recommendations of limiting tobacco use and of a healthy diet, low in refined sugars, saturated fats, and salt, and we cannot accept that economic interests undermine the efforts of the international health community to help populations change behaviors in a responsible way."

With many other health professionals, I rejoice in the stated commitment of the States to the fight against tobacco, for a healthy diet and more physical exercise, as well as medical interventions such as immunizations, early detection, screening, diagnosis and care, including palliative care.

Yet, I am not fully satisfied. These resolutions are totally incomplete and address only part of the problem. We all know that cancer, like the other chronic diseases, either included (diabetes, cardio- and cerebrovascular as well as respiratory diseases) or "forgotten" (reproductive and endocrine problems, neuropsychiatric diseases) from the field of this resolution, do not have solely behavioral risk factors that may be amenable to intervention at an individual level. Having done my MD thesis under the leadership of one of the pioneers in tobacco control, Pr Paul Fréour, I do not need to be convinced of the crucial need of a healthy living for the prevention of disease, including but not limited to avoidance of smoking. I spent years of my life as I still do, trying to act at all possible levels for convincing people and in particular the young not to smoke, to drink very little if any alcohol, to have a balanced healthy diet, and to indulge in physical exercise. Yet, close to 30 years in the field of cancer epidemiology for prevention convinced me that this is not enough. A significant, even if no one would agree of the precise estimation of its attributable risk, part of cancer is not due to genetics (in the classical restricted sense of alterations of the genome) and lifestyle. Having seen the number of cancer cases doubling over my career time, I conclude, after taking into account all causes of cancer (increase in population size, aging, screening, improvement in diagnostic methods, modifications of disease classification) the first two of which are easily taken into account through standardization of rates and the rest can be estimated by simulations, that there is a true, real increase in the occurrence of cancer in the world. The best example is childhood cancer rates, where the children cannot be said to be older than they previously were and for whom no screening (with the possible exception of neuroblastoma in a few countries) is being carried out, which have been regularly increasing, of the order of 1 to $1.5 \%$ per year in most European countries for the past 20 to 25 years. What are the causes? Genetics do not change in populations on such a rapid scale and I seriously doubt humankind will adapt to carcinogens over the coming centuries or millennia necessary for a classical Darwinian evolution. The role of lifestyle of course plays a role (tobacco, alcohol, diet, physical activity, sexual and reproductive life, sun exposure, use of drugs), but again this does not fully explain the increase. So, what are we left with? Hazard? "Chance"? Or the most logical culprit: the presence of ever-increasing thousands of toxic agents in the environment!

It is common knowledge that the air we breathe, the water we drink, the food we eat, and the objects we use every day contain chemical as well as physical carcinogens. The major difference between our present environment and the one of our grand or great grandparents is that we now all are daily exposed, from the time of conception (and even prior to that through exposures of the gametes) to death, to hundreds of chemicals (air and water pollutions, pesticide residues, chemical ingredients or contaminants of plastics, furniture, cooking pots, cosmetics, endocrine disruptors of numerous types and origins). Similarly we live surrounded by radiations, be they ionizing radiations (medical radiographic examinations, nuclear power plants, in normal functioning or in case of accidents (Three Miles Island, Chernobyl, Fukushima, and the next to be (in France?)) and nonionizing radiations (extremely-low frequency fields of high and very high-power lines, radiofrequency electromagnetic fields of cell and cordless phones, antennas, wi-fi, or most recent sources such as "intelligent" meters). I have testified in several countries of the world on these issues. I recognize not everything is known, in particular in terms of mechanisms, but yet there is evidence as to their danger to health. What should be done? Nothing, while waiting for "definitive" prospective studies which will take decades to produce results? My opinion as a doctor, a scientist, and a population health expert is that we know enough to recommend prevention and, when the data are limited, precaution. Exposures to noxious substances should and must be avoided, in particular when they are not necessary to life. It is fully logical to prescribe a drug known to be a carcinogen for treating and potentially curing someone with cancer. The risk (of a second occurrence of cancer) will be small compared to the benefit (not dying from cancer). But who will argue that we need to be exposed to hundreds of pesticide residues and other phyto agents to have perfectly shaped and shining red apples, tons of coloring, flavoring, texture agents to eat blue ice cream with exotic taste and flavor? Do we really need to wear tee-shirts or socks which thanks to nanoparticles may be worn several days without being washed because they destroy sweat odor? Do we need to spend our lives connected 24/7 through our computers and "smart" phones, just because we are no longer able to talk faceto-face with the person in next door office? Do we need to offer blue genetically modified carnations when violets exist? Why not, if these choices were free and devoid of 
risk? Unfortunately, although we may not know the full extent of the health risk, we know enough to be exceedingly suspicious of most of these exposures to which the whole population is exposed without their consent or not even a clear awareness of the reality of these exposures.

\section{The specific case of countries of the South and in particular of Africa}

\section{Per aspera (sic itur) ad astra \\ (Lucius Annaeus Seneca, 437)}

What I have been stating in the above lines applies to the whole world, with a global burden of cancer having gone from an estimated 6 million new cancer cases a year in 1980 to more than 12 millions in 2012 and keeps on increasing. In Africa alone, it is estimated that one million Africans will die each year from cancer by 2030 . The size and growth rate of this cancer epidemic on the continent should make it in the best of all possible worlds an absolute priority. Is this what we see?

No, not at all! The New York UN Summit stopped at making the most needed but yet totally insufficient recommendations, almost totally restricted to lifestyle. Despite what we had written in our letter "other exposures, beyond the ones which are amenable to behavioral interventions" were hardly mentioned. No environmental factors, with the exception of air pollution to which a few lines were devoted to, were included in the resolution. We had stated that "(w)e also urge for a serious consideration when dealing with occupational factors of disease, of the issues of child labor as well as the specificity of women in the workforce, in terms of sensitivity to potential toxics during reproductive years while also keeping in mind the issue of equal to men treatment and pay at a comparable position and with similar education, training, and experience.

Among the risk factors to be considered, the physicochemical pollution of air, water, food, soil, and objects of daily living is of major concern. This corresponds to the presence in our general, occupational and domestic living environment of carcinogens, teratogens, endocrine disruptors and other toxic agents, ranging from indoor and outdoor air pollution, poor-quality drinking water, food supply contaminated by pesticides and medicinal drug residues to exposures at the workplace, in particular in countries with no occupational medicine, industrial hygiene, or any other form of worker protection, and with frequent legal or illegal child labor."

The current specificity of exposures and diseases in the South is that the globalization of exposures is leading to the globalization of diseases and in particular cancer. When the late Calum Muir in the 1960s was drawing at the Interna- tional Agency for Research on Cancer (IARC), which had just been founded, the first world maps of cancers, a clear contrast existed between North and South. The so-called "developed" countries were characterized by cancers mostly linked to lifestyle and environment, such as lung cancer, breast cancer in women, testicular and prostate cancers. By contrast, "developing" countries had high rates of cancers linked to biological agents, such as liver, cervical or nasopharyngeal cancers. Over the decades, the IARC Globocan program and even before it was created the data from cancer registries in the world compiled in Cancer Incidence in Five Continents, have documented over the successive editions, trends of increasing rates in countries of the South for the cancers previously considered as "markers of civilization". What is the most likely cause of these trends? Again, some will argue that the answer is not known. But who will be brave enough to say that the fact countries of the North are exporting to the South their most dangerous products, from high tar cigarettes to banned pesticides and chemicals, while at the same time delocalizing the most polluting industries (work with asbestos, a compound which clearly cannot be manipulated safely, Seveso-Bhopal type industries, activities of deconstruction, from old boats to discarded electronic equipment or nuclear and other wastes) will not have any impact on the health of Africans or Indians and will not contribute even more than in countries of the North to pollution of mother Earth? I will only take one dramatic example. The most frequent cancer among African women in the past was cervical cancer, killing young women of reproductive age, whereas in the North cervical cancer drastically declined as from the 1960s, with an acceleration of reduction of mortality as well as incidence, with the setting up of screening programs using cervical cytology. The number of women now dying from cervical cancer in a country like France is less than 1,000 compared to almost 12,000 for breast cancer. In the past decades by contrast, cervical cancer did not diminish in Africa but breast cancer increased so greatly that it is now estimated to be the most common cancer in women, ahead of cervical cancer in some African countries. In the 1960's, breast cancer was hardly ever diagnosed in Africa. Now in a country like Nigeria, there were 18,935 breast cancer cases for 14,550 cervical cancer cases in 2008. Given that breast cancer kills more often than cervical cancer and means of treatment are often limited to surgery in parts of sub-Saharan Africa, this epidemic represents a huge tragedy, with the death of young women leaving behind them numerous orphans. It has to be acknowledged that we really do not know what the causes of breast cancer are in Africa. Most of these women have had several children, up to more than 5 and starting at a young age, which they did breast feed for an extended period of time. So what we have been saying in the North, since the seminal study of Janet Elizabeth Lane-Claypon (1877-1967) about the effect of 
reproductive life does not seem to apply in Africa. It is therefore of the utmost urgency to do etiological studies on this type of cancer.

\section{The need for action}

\section{Yes, we can! (Barack Obama, 2008)}

As already stated in the open letter: "(a)mong the risk factors to be considered, the physicochemical pollution of air, water, food, soil, and objects of daily living is of major concern. This corresponds to the presence in our general, occupational and domestic living environment of carcinogens, teratogens, endocrine disruptors and other toxic agents, ranging from indoor and outdoor air pollution, poor quality drinking water, food supply contaminated by pesticide and medicinal drug residues to exposures at the workplace, in particular in countries with no occupational medicine, industrial hygiene or any other form of worker protection, and with frequent legal or illegal child labor." We are concerned about the effects of these chemical and physical (ionizing and nonionizing radiations, such as EMF emitted by cell phones) agents in the population as a whole, but even more so among susceptible groups, such as women of reproductive age, children and disadvantaged individuals. The only effective way to protect the world population is to act at a global level, in particular through legislation at the national level and a framework convention at the international one.

The text of the UN Resolution needs to make clear statements and propositions such as the ones unanimously adopted during one of the preparatory meetings in Asturias which listed, among others the following key recommendations:

"1. Prevention of the environmental and occupational exposures that cause cancer must be an integral component of cancer control worldwide. Such prevention will require strong collaboration across sectors ... and among countries, and also with civil society and the media."

"4. All countries to adopt and enforce legislation for protection of populations, especially the most vulnerable populations, against environmental and occupational cancers."

"6. Corporations to comply with all rules and regulations for prevention of environmental and occupational cancers and to use the same protective measures in all countries, developed and developing, in which they operate."

These measures if they are implemented will have a much larger impact than the one on cancer. In fact, many carcinogens are also reproductive hazards or just simply toxic for several organs in humans (brain, kidney, liver, etc.). By removing them from our environment or at a minimum limiting exposure to them, we can significantly contribute to making the children of today and future generations healthier.
We kindly request you to consequently complete the list of diseases and priority risk factors to reflect up to date scientific evidence and demonstrate the care Governments take of the health of their populations, being audacious enough to put the health of all ahead of the wealth of the few."

We never received any reply.

\section{North-South collaboration}

\section{Primum, non nocere (Hippocrate, $400 \mathrm{BC}$ ) Love never fails (Paul, 1Corinthians 13:8)}

In order to make significant progress in the fight against cancer in Africa, much more needs to be done in cancer epidemiology. Knowledge may not always be power but having valid data does help in convincing politicians and other decision makers to act, i.e., to decide to allocate some funds for population health action. This is the crux of the matter. Countries of the North have been willing to put funds aside for the research on AIDS, including in Africa, most probably because that infectious, transmissible disease had made its way to their own populations and authorities had research questions which could not be adequately addressed in their countries, due to the very small number of people who were infected with HIV. Africa was and still is the best research and testing ground for such projects. For cancer, the situation is completely different. Cancer institutions and charities of the North feel they know quite a lot on some cancers in their own countries and do not see why they should allocate money to problems they (wrongly?) consider to have solved. I personally have the painful and frustrating experience of desperately searching for funds to conduct case-referent studies pertinent to the African continent. They never fit in any cancer call for projects, which specifically in France, for example, exclude any possibility of spending money allocated in other countries. Where, therefore, am I going to look for the necessary funds to study the feasibility of a thorough assessment of the role of infectious agents in adult and pediatric cancer in Africa, going beyond what is already known? Who is going to fund some cheap case-referent studies on breast or digestive cancers in Africa, where with much less than $100,000 €$ collaborators are ready to start working tomorrow in five to ten African countries? Usual sources of cancer funding in France are not interested. What am I going to tell my African colleagues? I feel ashamed for my country and its institutions. We do not live in an isolated island. The world is one and what is affecting some population groups is pertinent to others. May be the situation will change and the impact of climatic change on spread of vectorial diseases will lead to a renewed interest in shrinking fields of expertise, where France was long leader such as in tropical medicine or parasitology. The problems 
have not been solved and we need to keep working at them. In fact, the separation between transmissible and non transmissible diseases is a huge mistake, ignoring the links between the two which may be pertinent not only for themselves but more generally for crucial physiopathological mechanisms of inflammation and immunity which could represent new scientific knowledge also in the cancer field. In Africa, an integrated holistic horizontal approach to both transmissible and non transmissible diseases could also save money, compared to specific approaches for vertical diseases.

\section{Conclusion}

Never doubt that a small group of thoughtful, committed people can change the world. Indeed, it is the only thing that ever has (Margaret Mead, 1949)

Last but not least, why are we on earth if not to love and help each other?

Good luck to the next generation of doctors, scientists and politicians to make our world a better place where to live and work!

Acknowledgments Without my colleagues in Africa, I would not be able to do anything. I want to thank the ones
I worked with in the past during my days at IARC, Pr Fahrat Ben Ayed and Dr Wided Ben Ayoub (Tunisia), Pr Mohamed Bartal and Dr Imane Dari (Marocco), Pr Mohamed HamdiCherif (Algeria); the ones I am working with now (thanks to HIV!), Pr Clement Adebamowo, Dr Manhattan Charurat and Dr Emmanuel Oga (Nigeria), Pr Paul N'Dom (Cameroun), Pr Djimon Marcel Zanou (Benin), Pr Emmanuel Bissagnéné, Dr Appollinaire Horo, Dr Serge Eholié, Dr Didier Ekouevi, Dr Eugène Messou, Dr Albert Minga (Côte d'Ivoire), Dr Mamadou Traoré and Dr Moussa Maïga (Mali); and the ones I have recently started working with, specifically on cancer, despites the lack of any funding but with whom I hope we will do much more, simply because the health of African populations deserve it: Dr Boubakar Traoré (Mali), Dr Beatrice Wiafe-Addai (Ghana), Dr Habakkuk Yumo (Cameroun), Dr Chukwanugo Ogbuagu and Dr Aderemi Oluyemi (Nigeria). and Wilfried Affodegon (Benin). Finally I want to thank my colleagues from the North who are sympathetic to my efforts and fight, Pr Denis Malvy from the Centre René Labusquière at Bordeaux Segalen University, France and Pr Sten Vermund at Vanderbilt Institute for Global Health, Nashville, USA.

The opinions expressed in this paper are solely mine and should not be taken as official positions of the Inserm nor of the Bordeaux Segalen University. 